\title{
«Mein Lesebuch»: un nuevo tipo de antología literaria
}

Fernando Magallanes

\section{Introducción}

En 1976 aparece en la República Federal de Alemania un libro de Hubert Fichte titulado «Mein Lesebuch» (Mi libro de lectura). Se trata del primero de una serie que por el momento apenas ha llamado la atención de críticos y estudiosos de la literatura alemana actual. Además de Fichte, han publicado su «Lesebuch»: Alfred Andersch, Joachim-Ernst Berendt, Heinrich Böll, Michael Andreas Helmuth Ende, Max von der Grün, Peter Härtling, Eckhart Henscheid, Robert Jungk, Walter Kempowski, Pavel Kohout, Günter Kunert, Horst-Eberhard Richter, Luise Rinser, Peter Rühmkorf y Wolf Wondratschek. Prácticamente todos ellos son escritores alemanes, salvo alguna excepción: Berendt, por ejemplo, no es un literato, sino un profesional de la radio, especialista en música de Jazz, sobre la que ha publicado algunos títulos; Richter, a su vez, es un hombre conocido en el mundo del psicoanálisis; y Kohout, checoslovaco, sería ejemplo de autor no alemán que ha escrito su «Lesebuch».

Pero, ¿quées «Mein Lesebuch»? Ateniéndonos a su estructura y a la intencionalidad del autor daríamos la siguiente definición: textos formados por la reunión de fragmentos de obras literarias que el autor selecciona según su propio gusto personal de entre aquellas que más valor han tenido para él como lector, y que se presentan en un volumen bajo el título de «Mein Lesebuch».

En nuestra opinión, «Mein Lesebuch» enlaza, de una parte, con la antología tradicional, $y$, de otra, con el género autobiográfico. Del término «Lesebuch» -antología- toman el nombre los libros de la serie que nos ocupa y son consecuencia histórica de los libros de lecturas escolares; se trata, pues, de un parentesco en los aspectos nominal y estructural el que une a ambos tipos de textos; y, desde el punto de vista de la intencionalidad del autor, «Mein Lesebuch» es literatura autobiográfica porque consiste en la reunión de fragmentos subjetivamente seleccionados que, por lo tanto, hacen referencia al mundo intelectual del autor. 
Las lecturas preferidas efectuadas por éste a lo largo de su vida, y que ahora se presentan en un volumen, nos acercan a su personalidad; por eso, no cabe la menor duda de que nos hallamos ante unos textos de carácter autobiográfico que, junto a otros, son exponente del incremento que este tipo de literatura ha venido experimentando en la República Federal de Alemania, a partir de la llamada «nueva subjetividad» que hace su aparición a comienzos de la década de los años setenta.

\section{Conexión con la antología escolar (Schullesebuch)}

Tipológicamente distinguimos dos clases de «Lesebuch» cuyo criterio diferenciador nos lo proporciona, esencialmente, la finalidad con que nace uno y otro: escolar y divulgativo. Éste, de menor trascendencia social, comprende todo tipo de antologías que tienen por misión proporcionar placer estético al consumidor y rendimiento comercial a la editorial. Históricamente es, sin embargo, el texto escolar el que ha tenido especial importancia por ser fuente de conocimientos y medio auxiliar para la formación de los jóvenes estudiantes. Si bien el concepto «Lesebuch» no surge en Alemania hasta fines del siglo XVI ${ }^{1}$, el texto de carácter antológico hace su aparición ya en la Edad Media y se desarrolla hasta la actualidad adoptando diferentes manifestaciones según los momentos históricos concretos. Así, un primer tipo de «Lesebuch» se desarrolló cuando la burguesía menos privilegiada comenzó a emanciparse del dominio feudal. El estamento social que tenía el monopolio de la cultura se ve obligado a ceder, y surge el «Lesebuch» como técnica de enseñanza utilizado por capas más amplias de la población. La crestomatía tuvo, por el contrario, un carácter conservador como continuadora que era de la tradición literaria de la Antigüedad, aunque en su conjunto supuso un paso progresista puesto que se acercó a la lengua popular y abandonó paulatinamente el uso del latín, lo que posibilitó la formación lingüística y literaria de un mayor número de personas. El libro de cosas surge y se afianza a medida que la burguesía gana terreno al dominio feudal; introduce contenidos no permitidos anteriormente por el clero y los señores feudales. Por su parte, el Libro de enseñanza moral es una consecuencia de la Ilustración, y da paso al «Lesebuch» del Romanticismo que terminará convertido en instrumento manipulado al servicio de determinadas tendencias políticas. Por último, el libro de trabajo para la clase de literatura es un producto de la sociedad democrática, que aparece, por tanto, como tal recientemente, y cuyo objetivo es la enseñanza de la literatura ${ }^{2}$.

Pues bien, «Mein Lesebuch» sería una variante del «Lesebuch» que denominábamos divulgativo. El alejamiento, por tanto, de los textos que componen la serie «Mein Lesebuch» del «Lesebuch» escolar es grande. Sin embargo, históricamente además del

\footnotetext{
${ }^{1}$ Cfr.: Hermann Helmers, Geschichte des deutschen Lesebuchs in Grundzügen. (Stuthgart: Emst Klett Verlag, 1970), Nota 3, p. 13.

${ }^{2}$ En la denominación de los distintos «Lesebücher» (antologías) hemos seguido a H. Helmers, op. cit., quien propone para cada uno los siguientes nombres: «Leselembuch», «Crestomatie», «Sachbuch», «Morallehrbuch», «Gesinnungslesebuch» y «literarisches Arbeitsbuch».
} 
evidente parentesco nominal, es preciso considerar a la antología escolar como antecedente mediato, pues de ella toman su forma y estructura los actuales «Lesebücher», que componen la serie «Mein Lesebuch». Así pues, partimos de la premisa según la cual el fenómeno «Mein Lesebuch» surge de un determinado tipo de texto escolar que, con el paso del tiempo, la evolución y el desarrollo cultural, sufre una serie de bifurcaciones dando origen a diferentes clases de antologías y, a través de éstas, como un tipo especial de antología, aparece «Mein Lesebuch». En resumen, desde una perspectiva histórica, teniendo en cuenta por consiguiente fases o etapas intermedias, «Mein Lesebuch» es una derivación del «Schullesebuch» (libro de lectura escolar). La diferencia esencial que media entre uno y otro es de orden cualitativo: en un caso domina la subjetividad; en el otro, la objetividad.

Existen además, otros rasgos distintivos. Funcionalmente, por ejemplo, también se diferencian. La función intrínseca que tiene toda antología escolar (y no como consecuencia del valor en sí de los textos, sino del que representan como comunicación) no es propia de «Mein Lesebuch»; esa función primaria carece aquí de sentido. Esto es una consecuencia de que «Mein Lesebuch» participa sólo de la funcionalidad estética; la informativa es propia del libro escolar.

Desde la perspectiva teleológica la diferencia es clara: puesto que «Mein Lesebuch» va dirigido a un público más amplio y heterogéneo, por lo menos en teoría, su finalidad en absoluto tiene ya que ver con el didactismo y la formación, propios del texto escolar. $\mathrm{Y}$, aunque «de tales antologías no es responsable ninguna comisión oficial» ${ }^{3}(\mathrm{y}$, por tanto, el peligro de un dirigismo que obedezca al dictado de cambiantes sistemas políticos como sucede en los libros escolares- no puede producirse), esto no evita, naturalmente; el problema de la instrumentalización de «Mein Lesebuch». Si en el libro escolar es, o ha podido tender a ser a lo largo de la historia, más que nada ideológica o política, «Mein Lesebuch» es un producto que se presta a la manipulación estética y editorial por la posibilidad que brindan libros de esta naturaleza de relanzar un determinado tipo de literatura. En tal sentido, «Mein Lesebuch» corre el riesgo de servir a intereses extraños (comerciales). Esto, sin embargo, no va en detrimento de la finalidad de los textos (ofrecer aquellos fragmentos que han sido importantes para el compilador, independientemente de los criterios utilizados por la editorial a la hora de seleccionar posibles autores de «Mein Lesebuch») y, por ello, el consumidor no es objeto de fraude; mientras que en el ámbito escolar la manipulación ideológica del alumno es atentatoria contra su persona al menos desde un punto de vista ético y, sobre todo, si se considera la literatura que se ofrece al estudiante no sólo como fin en sí, sino como medio de alcanzar una educación integral. Por otra parte, estas metas -compatibles y deseables en el texto escolar- se reducen a una sola en «Mein Lesebuch», en donde el ideal es que la literatura sea exclusivamente fin en sí respondiendo a una actitud sincera del compilador.

Una consecuencia del objetivismo que debe imperar en el libro antológico escolar es la concepción previa de su disposición y contenido, para lograr alto valor estético y conexión con la realidad, ya que entendemos que además de literatura de calidad debe

${ }^{3}$ K. Meyer-Herzog, «Bewusst subjektiv», en Basler Zeitung, 27.12.1978, p. 35. 
aportar información sobre la realidad pretérita y contemporánea del alumno. Distinto es el caso de «Mein Lesebuch»; su subjetividad, -y, consecuentemente, su concepción- no le obliga a conectar con la realidad de manera tan directa. Lejos de estar preconcebido, su formación es espontánea; cuanto más espontáneamente se deje llevar el autor tanto más subjetivo y auténtico será su «Lesebuch».

Una última diferencia importante es, a nuestro juicio, el que la antología escolar pueda y deba ser intermediaria entre lector y obra completa, en tanto que «Mein Lesebuch» no tiene por qué serlo, salvo que el autor haga indicaciones en sentido contrario.

Vistos los aspectos divergentes, mencionemos ahora los puntos en que convergen «Schullesebuch» y «Mein Lesebuch». Aparte del parentesco histórico señalado más arriba, observamos que la conexión entre los dos tipos de antología se produce, fundamentalmente, en los siguientes aspectos:

1) Formalmente, ambas manifestaciones de «Lesebuch» son idénticas: se trata siempre de reunión de fragmentos de obras literarias. El problema de la mutilación es más grave en el libro escolar que en «Mein Lesebuch». En este caso, el párrafo escogido por el autor es el que más interesa leer por ser su repercusión en la propia obra del autor de mayor importancia. Es más, puede suceder que el resto de la obra carezca de importancia para el autor $y$, consecuentemente, de interés para gran parte del público, pues no hay que olvidar que quien lee «Mein Lesebuch» lo hace atraído por el nombre del autor-compilador, no por el de los autores de los párrafos en él contenidos.

2) Si cualquier antología tiene su razón de ser por la imposibilidad de conocerlo todo -y por eso el «Lesebuch» en la escuela es necesario-, esto es también aplicable en el caso de «Mein Lesebuch». No tanto por la posible dificultad de abarcar todo lo que el autor de «Mein Lesebuch» haya leído, sino porque parte de sus lecturas son superfluas o banales en lo que se refiere a la posible influencia en su creación literaria. Además, algunos párrafos escogidos personalmente por un autor pueden ser suficientes para conocer sus preferencias, inclinaciones e influencias en su propia creación artística. Tales párrafos, si son los que más le han impresionado como lector, forman un todo y ofrecen una visión de conjunto sobre el autor de «Mein Lesebuch».

3) «Schullesebuch» $y$ «Mein Lesebuch» son un experimento. El primero es un experimento pedagógico; el segundo, un experimento editorial en el que la calidad de los textos presentados es irrelevante, no así la de los autores seleccionados para presentar su propio «Lesebuch», ya que del renombre que tales escritores tengan dependerá en gran medida el buen o mal éxito comercial de la serie «Mein Lesebuch».

4) $\mathrm{El}$ «Schullesebuch» supone un lanzamiento de lo mejor; contiene fragmentos de la mejor literatura que se puede ofrecer a un estudiante. A su vez, en «Mein Lesebuch» se lanza también lo mejor; pero lo que a mí personalmente, autor de $m i$ «Lesebuch», me parece que es lo mejor, lo que más me ha impresionado, la literatura que más ha influido en mi vida, en mi pensamiento o en mi propia forma de escribir. Por ello, estéticamente ambas antologías son coincidentes. Desde diferentes perspectivas confluyen, sin 
embargo, en presentar al lector literatura de calidad ${ }^{4}$ seleccionada, en un caso, objetivamente; en otro, subjetivamente.

5) En ambos casos existe también la dificultad de reunir los textos adecuados. En el libro escolar la dificultad viene determinada por el intento de lograr una finalidad concreta de alcance pedagógico. En muchos casos no es fácil establecer si tal o cual tex to es mejor (más apropiado) que tal o cual otro. El autor de «Mein Lesebuch» se enfrenta con un problema similar: no es sencillo, a veces, escoger de entre las lecturas efectuadas aquellas más representativas y que subjetivamente se consideran como las mejores. La espontaneidad implica que el compilador se deje llevar de los efectos que las lecturas han producido en él, independientemente de los autores, del puesto que ocupen en la literatura universal o de otraś circunstancias extrañas a las lecturas en sí. Pero esa espontaneidad puede suponer a su vez un riesgo. Es posible que el autor no se dé cuenta de que algunas lecturas le han influido más que otras. Inconscientemente puede haber una influencia en su estilo literario, en su pensamiento o incluso en su forma de vivir. Por eso, la labor selectiva de los textos que el autor de «Mein Lesebuch» ofrece puede ser tan difícil como en el caso del «Lesebuch» escolar.

\section{Configuración del género «Mein Lesebuch» dentro del ámbito de la literatura autobiográfica}

Estimamos que «Mein Lesebuch» es un ejemplo más del auge autobiográfico -y en concreto de lo autobiográfico-documental- que experimenta la literatura de la República Federal de Alemania en los años setenta. «Mein Lesebuch» es algo nuevo y original; es un concepto nuevo de antología. Es literatura, pero no creación; sencillamente recopilación de textos literarios. Recopilación hecha según el gusto personal del compilador. Luego, mérito como obra de arte propia es evidente que no lo tiene. El valor que se le debe atribuir lo tiene por ser o poder llegar a ser parte de un proyecto más amplio: una autobiografía intelectual. Los textos que el autor reúne en una antología subjetivamente concebida constituyen, en nuestra opinión, parte importante para la elaboración de su propia autobiografía. Encaja, pues, «Mein Lesebuch» dentro de ese tipo de escritos que Georges May ${ }^{5}$ sitúa a medio camino entre la crónica o reportaje, caracterizado por el distanciamiento del autor, y la autobiografía religiosa, muy apegada al yo. En la autobiografía intelectual el yo del escritor tiene, por lo tanto, una presencia importante, pero sin llegar al caso extremo de la autobiografía religiosa. En «Mein Lesebuch» el yo no está presente de manera directa sino referencial, puesto que no es el autor material de los textos; por eso, estos sólo son material útil, un elemento auxiliar más para la elaboración de la autobiografía intelectual del autor; es decir, para un tipo

\footnotetext{
${ }^{4}$ Aunque se ha dicho que la calidad de los textos es irrelevante en «Mein Lesebuch» en el sentido de que lo que interesa es que se reúna la literatura que ha ejercido influencia en el autor, es evidente que, en la mayoria de los casos, el autor de «Mein Lesebuch» habrá sido lector de literatura de calidad.
}

${ }^{5}$ Cfr. Georges May, L'autobiographie (Paris: Presses Universitaires de France, 1979). 
de autobiografía en donde lo esencial es revelar al lector el desarrollo intelectual o ideológico del autor, el proceso de formación de sus ideas. «Mein Lesebuch» se integra, por consiguiente, en el tipo de autobiografía escrita por necesidades de comunicación. Quien hace un «Lesebuch» subjetivo no intenta vengarse de nada, su meta no es desmentir calumnias o justificar determinado tipo de actuaciones; tampoco es un nostálgico el autor de un «Lesebuch» subjetivo; no rememora la niñez como una época añorada ni quiere luchar contra el tiempo, como sucede en otros subgéneros autobiográficos. Es su intención de expresar algo a los demás, su alma de escritor, lo que le lleva a descubrir los secretos de su existencia intelectual.

Profundicemos un poco más y veamos algunos de los porqués de «Mein Lesebuch» como literatura autobiográfica.

Quizá sea la autobiografía estudiada por Picard ${ }^{6}$ aquella a la que más se parezca «Mein Lesebuch». El detalle concreto, la experiencia precisa, el orden cronológico pueden tener en «Mein Lesebuch», lo mismo que en la nueva autobiografía francesa, un relativo valor. El caso de Andersch es significativo a este respecto. A él no le interesa una o varias obras determinadas; busca un tipo de literatura (la descriptiva) que, en conjunto, ha sido decisiva en su forma de escribir. Con el «Lesebuch» subjetivo se busca también la verdad en uno mismo -como dice Picard ${ }^{7}$ - mediante la atención prestada a aspectos determinados de una vida que en este caso es el bagaje de lecturas efectuadas. $Y$, por tratarse de una profunda introspección sin distorsiones del mundo exterior, el resultado es de gran autenticidad.

También desde la perspectiva tradicional «Mein Lesebuch» presenta claros rasgos que le identifican con la literatura autobiográfica. En buena medida, las precisiones de los teóricos del género son aplicables a «Mein Lesebuch». Si, como dice $\mathrm{Misch}^{8}$, la autobiografía se diferencia por el contenido no por la forma y, como manifestación vital, requiere un superior estadio de la cultura, también «Mein Lesebuch» parte de presupuestos semejantes: formas y técnicas literarias son irrelevantes; de manera que lo que interesa es el peso que los textos han ejercido en el autor. Sobre un autor que vive un momento histórico que hace posible productos del tipo «Mein Lesebuch» por existir conciencia de la propia identidad, lo que exige el previo desarrollo de un tipo de sociedad: la burguesa. El autor de «Mein Lesebuch», consciente de su identidad, inicia con su «Lesebuch» un proceso de autorreflexión, de manera que si la autobiografía -como diría Neumann 9 - es la historia de la formación de una individualidad, «Mein Lesebuch» como parte integrante de un proyecto más amplio de autoindagación personal es la historia de la formación de un aspecto de esa individualidad.

\footnotetext{
${ }^{6} \mathrm{Cfr}$. Hans Rudolf Picard, Autobiographie im zeitgenössischen Frankreich. Existentielle Reflexion und literarische Gestaltung. (München: Wilhelm Fink Verlag, 1978).

${ }^{7}$ Cfr.: H. R. Picard, op. cit., p. 9.

${ }^{8}$ Cfr.: Georg Misch, Geschichte der Autobiographie. Erster Band: Das Altertum.-Erste Hälfte. Dritte Auflage. (Frankfurt am Main: Verlag G. Schulte-Bulmke, 1949).

${ }^{9}$ Cfr.: Bernd Neumann, Identität und Rollenzwang. (Zur Theorie der Autobiographie). (Frankfurt am Main: Athenăum Verlag, 1970), pp. 5-6. Neumann parte de un principio heurístico de Misch, según el cual la historia de la autobiografia ha de entenderse como historia del desarrollo de la individualidad humana.
} 
«Mein Lesebuch» es, por lo tanto, literatura autobiográfica. Cualquiera que sea el concepto que se tenga de autobiografía es aplicable a «Mein Lesebuch». Así, por ejemplo, autobiografía entendida como descripción de la vida de una individualidad a través de ella misma; o como reflejo del desarrollo de un microcosmos dentro del proceso histórico; o como medio de autoconocimiento y autocomprensión para conocer la propia identidad; o, en fin, como intención de investigar sobre uno mismo. Tales concepciones del hecho autobiográfico, de Misch, Klaiber, Pascal y Wuthenow ${ }^{10}$ respectivamente, bien pueden remitirse a «Mein Lesebuch» por ser parte de la «descripción de la vida de una individualidad a través de ella misma», o «reflejo del desarrollo de un aspecto de un microcosmos», y naturalmente es también «medio de autoconocimiento y autocomprensión» e «intento de investigar sobre sí mismo».

«Mein Lesebuch» es también si no un género, sí un conjunto de elementos utilizados por un género literario mediante el cual se exterioriza la conciencia individual como conciencia de la personalidad. Con un «Lesebuch» subjetivo se puede penetrar en esa conciencia; el lector puede descubrirla mediante la representación y exteriorización de la personalidad intelectual del autor a través de los textos elegidos por él. Ahora bien, porno ser aún «Mein Lesebuch» autobiografía, sino sólo proyecto de obra autobiográfica, no podemos pretender hallar identidad entre personalidad del autor (entiéndase compilador) y personaje (personajes de los textos reunidos); tal identidad sería absurdo buscarla. Lo único que hay en este nivel de elaboración, previo a la obra autobiográfica total, que supone el ensamblaje de textos subjetivamente seleccionados, es la aceptación y asunción de lo creado por otro y que ha pasado a formar parte del yo.

Por otro lado, en el procedimiento que utiliza el autobiógrafo ( $y$ no nos referimos aquí a quien hace una autobiografía intelectual, sino a aquel que observando su pasado nos narra su vida) existe un matiz que lo aleja del autor de «Mein Lesebuch». El autobiógrafo acomete su labor con la previa comprensión del significado de su vida pretérita; esto es, tiene muy cercano el pasado porque fueron acciones, momentos vividos por él mismo e indisolublemente ligados a él. Nadie más pudo ser protagonista de sus acontecimientos. El autor de «Mein Lesebuch» carece de una "previa comprensión» tan precisa, como consecuencia de no existir identidad entre él mismo y su «Lesebuch», sino sólo influencia que los textos ejercieron en el pasado sobre él. De tal forma que el autor de «Mein Lesebuch» carece de la nitidez con que el autobiógrafo contempla su vida pasada, lo que le obliga a reunir los textos empleando un procedimiento analítico y a examinar detenidamente su experiencia como lector, o bien a dejarse llevar del subconsciente (como hace Kempowski, por ejemplo) y de la intuición. En ningún caso se da, como vemos, una previa comprensión -al menos tan aproximada como en la autobiografía- del significado de los hechos -hechos de lectura-pretéritos.

La consecuencia inmediata de este matiz en el procedimiento de elaboración de la autobiografía y del «Lesebuch» subjetivo, o sea, la presencia o ausencia de la previa

${ }^{10}$ Cfr.: G. Misch, op. cit. Theodor Klaiber, Dic deutsche Selbstbiographie. Berschreibungen des eigenen Lebens. Memoiren. Tagebücher. (Stuttgart: J. B. Metzlersche Verlagsbuchhandlung, 1921). Roy Pascal, Die Autobiographie. Gehalt und Gestalt (Stuttgart Berlin Koln Mainz: W. Kohlhammer Verlag, 1965). RalphReinerWuthenow, Das erinnerte Ich. Europäische Autobiographie und Selbstdarstellung im 18. Jahrhundert (München: Verlag C. H. Beck, 1974). 
comprensión del pasado, es la diferencia abismal que media entre el autobiógrafo y el autor de «Mein Lesebuch». El primero es un creador, un artista, un literato; el otro no. El autobiógrafo, al tener a mano el elemento fundamental, su vida, necesita darle forma literaria, crear, en una palabra. El autor de «Mein Lesebuch» no tiene tan fresca la experiencia pasada, la experiencia de lectura, porque son lecturas de textos compuestos por otros, no «vividos» (escritos) por él mismo, como le sucede al autobiógrafo, y por eso su labor consiste simplemente en analizar esa experiencia de lectura y una vez descubierta, limitarse a ofrecernos los textos, pero sin que intervenga para nada la creatividad, elemento fundamental en la obra literaria. Desde esta perspectiva, «Mein Lesebuch» carece naturalmente de valor ${ }^{11}$; no podemos decir que el autor ha escrito un libro o que ha creado una bora de arte propia ${ }^{12}$.

Salvo la diferencia apuntada, en lo demás el procedimiento es similar tanto en la autobiografía como en «Mein Lesebuch». La primera muestra la vida como proceso; el segundo muestra un proceso de formación intelectual. En ambos casos se actualiza el pasado; el autor de «Mein Lesebuch» interpreta su pasado como lector, porque el recuerdo implica interpretación actual del pasado desde una posición de experiencia acumulada. Y no se trata, además, de un simple repaso del pasado, como señala Gusdorf ${ }^{13}$ en el caso de la autobiografía; también en «Mein Lesebuch» se valora el pasado. La sola elección de los textos supone de por sí una valoración frente a otros, de tal forma que podríamos decir que el autor de «Mein Lesebuch» proyecta el transcurso de su experiencia de lectura mediante la reorganización de obras leídas y la elección y plasmación de textos considerados importantes por él mismo, porque «el recuerdo consciente o inconscientemente- sólo guarda aquellas experiencias que consideramos valiosas» ${ }^{14}$. Y eso explica el valor inmanente de «Mein Lesebuch», lo mismo que indica Hamack $^{15}$ para la autobiografía: la ausencia de rivalidad o competencia y el ser uno mismo la meta que se propone el autor hace del «Lesebuch» subjetivo un libro con un valor per se; valor que le viene de no poder ser hecho por nadie más que por el propio autor como sucede en el caso de la autobiografía. Uno mismo, decíamos, es la meta que se propone el autor de «Mein Lesebuch»; y, efectivamente, porque pese a no ser el propio autor el eje sobre el que gira la narración, como sucede en la autobiografía, los textos se eligen púesto que cumplen una función para el compilador. Sin esa función

\footnotetext{
${ }^{11}$ Nos referimos a valor atribuible al compilador, evidentemente, el valor como obra de creación referido a los autores de los textos compilados es otro asunto.

${ }^{12}$ Esta es la razón por la que, sin duda, en el libro Heinrich Böll de la serie «Rowohlts monographien» en un apéndice final que reúne la producción literaria de Böll, Mein Lesebuch aparece bajo el epígrafe «Herausgebertätigkeit» (actividad editora) y no en el correspondiente a «Autobiographische Schirhften» (escritos autobiográficos).

${ }^{13}$ Cfr.: Georges Gusdorf, «Conditions et limites de l'autobiographie», en Formen der Selbstdarstellung. Analekten zu einer Geschichte des literarischen Selbstportraits, Festgabe für Fritz Neubert. Hrsg. Günter Reichenkron; Erich Haase, (Berlin: 1966), 105-121.

${ }^{14}$ En Albrecht Lehmann, Erzählstruktur und Lebenslauf. Autobiographische Untersuchung (Frankfurt am Main New York: Campus Verlag, 1983), p. 22.

${ }^{15}$ Cfr.: Axelvon Hamack, «Die Selbstbiographie - ihr Wesen und ihre Wirkung», Universitas, 10 (Stuttgart: 1955), 689-698.
} 
«Mein Lesebuch» no tendría razón de ser, y es en ese sentido en el que sirve a la consecución de la meta a la que nos referíamos: el propio autor.

Otro punto coincidente entre autobiografía y «Mein Lesebuch» podemos verlo en el hecho de que lo mismo que cada vivencia subjetiva tiene significación para el todo (vida vivida) en la obra autobiográfica, un párrafo u obra concreta tiene para el autor de «Mein Lesebuch» una significación dentro de su lectura total, dentro de la influencia que toda una experiencia de lectura ejerce en él. Sin embargo, la necesidad del elemento ficcional es indispensable para dar forma literaria al todo en la autobiografia: si faltara la ficción estaríamos ante un currículum. Mientras que en «Mein Lesebuch», en cambio, la ficción desaparece dejando de ser -según hemos dicho- creación artística; y, en realidad, tampoco hace falta si ha de ser solamente documentación para una posible o futura autobiografía intelectual. La ficción o la trama diríamos que se sustituye por una especie de hilo conductor que surge por sí mismo entrelazando los textos, como sucede en los «Lesebücher» de Böll, Andersch, Kunert o Kempowski a tenor de lo que nos dicen en sus prólogos respectivos. Ese hilo conductor es el que confiere unidad y totalidad a un «Lesebuch» subjetivo. Si en un primer momento pudiéramos pensar que en obras de este tipo lo que senos ofrece es un conjunto de textos inconexos, un estudio pormenorizado de los «Lesebücher» revelaría cómo esa aparente desconexión no es sino formal. El «Lesebuch» subjetivo es también una unidad, es totalidad restringida a una parte de la esfera intelectual del autor. De la misma manera que no sólo la obra individual es un todo (unos fragmentos escogidos de un poeta o prosista forman un todo a su vez, una unidad en la que se contienen los elementos necesarios para abarcar al autor en su totalidad), «Mein Lesebuch» conforma una unidad y nos muestra la totalidad de un aspecto del desarrollo intelectual de un individuo. Porque, además, si «el individuo experimenta el proceso vital como una totalidad», según nos dice Albrecht Lehmann ${ }^{16}$, es evidente que la experiencia pasada forma un todo que el autobiógrafo tiene presente en el momento de redactar su obra; $y$, de igual manera, las lecturas que el autor de «Mein Lesebuch» reúne por ser las que más significaron para él las concibe como un todo dentro de su desarrollo intelectual. El caso más claro lo volvemos a tener en Andersch: la descripción ha conformado, sin duda, una parte de su intelectualidad.

Detengámonos ya, para terminar, en un último aspecto: el tema de la veracidad. Autobiografía y «Mein Lesebuch» suponen una toma de conciencia; toma de conciencia de la totalidad a la que nos referíamos antes y que se forma paulatinamente y sin solución de continuidad. Si partimos de la sinceridad en el autobiógrafo y en el autor de «Mein Lesebuch", el resultado es cierto y objetivo porque son productos concretos de la experiencia vivida o leída; expresión -en palabras de Misch- de la relación entre un yo y su realidad circundante. Cierto y objetivo no significan, sin embargo, lo mismo que verdadero, adjetivo que adquiere connotaciones específicas cuando se habla de literatura autobiográfica, pues en ella la verdad está más en relación con la intención subjetiva del autor que con la realidad objetiva de lo que se dice. El problema de la verdad que se plantea al tratar el concepto de autobiografía es también planteable, en parte, en el caso de «Mein Lesebuch». En un primer estadio de la cuestión hay que preguntarse si el autor

${ }^{16}$ A. Lehmann, op. cit., p. 284. 
ha reunido los textos desde una perspectiva subjetiva. En caso de no ser así, «Mein Lesebuch" pierde todo su valor como antología personal y se convierte en oportunidad de proyección de una serie de nombres u obras por cualesquiera motivos, ya sean comerciales o de cualquier otra índole. En caso contrario, si el autor reúne los textos según su preferencia personal, tendríamos que otorgar a «Mein Lesebuch» un carácter de autenticidad porque la verdad es propia del recuerdo, como diría Misch, y pese a que los recuerdos la puedan empañar, según opina Klaiber, ya que el paso del tiempo produce un efecto contaminante o de mezcla de unos recuerdos con otros que pueden desdibujar la verdad, siempre permanece -y el propio Klaiber lo reconoce- una verdad inmanente. Pero, además, no sería exagerado afirmar que «Mein Lesebuch» es quizá más auténtico que cualquier otro tipo de literatura autobiográfica, pues en él el autor ni siquiera tiene la posibilidad de intercalar elementos de ficción. Todo el libro es una verdad; verdad como propio conocimiento de la personalidad autobiográfica y verdad extraída de la experiencia personal, según nos diría Pascal. No nos queda, pues, más solución que admitir la verosimilitud absoluta desde el momento en que el autor selecciona de aquellas de sus experiencias lo que fue importante y valioso para él desde su propio punto de vista.

Si antes decíamos que el problema de la verdad era sólo planteable en parte es porque los dos tipos de verdad, la íntima y la histórica, de las que se puede hablar en la autobiografía en general, se reducen sólo a la primera en el caso de «Mein Lesebuch». Por ello, la contradicción entre verdad (objetiva o histórica) y recuerdo, muy natural en la literatura autobiográfica, carece de sentido en «Mein Lesebuch», cuyo carácter autobiográfico se limita exclusivamente a una de las esferas más íntimas del individuo: el campo intelectual. Vemos, entonces, que «Mein Lesebuch» encaja en el tipo de verdad al que alude Misch cuando dice que no son imaginaciones lo que el autobiógrafo plasma en el papel, sino extractos literarios (categorías de vida en el caso de la pura autobiografía) que ahora -diríamos- se objetivan en «Mein Lesebuch». Es la propia vida la que se objetiva en el caso de la autobiografia; ahora se trata de una parte de la experiencia intelectual la que se objetiva en «Mein Lesebuch», porque la conciencia subjetiva del autor está también ligada a ella en cada acto de recuerdo que se transforma en algo objetivo y con forma de verdad.

Sin embargo, y de la misma manera que la esencia pura de la personalidad del autobiógrafo permanece inescrutable-al lector, la esencia de la personalidad intelectual del autor de «Mein Lesebuch» es inaccesible. Sólo la descubriremos o, mejor dicho, nos aproximaremos a ella, si buscamos en su propia obra literaria. «Mein Lesebuch» no nos proporciona más que una referencia.

\section{El fenómeno «Mein Lesebuch» en el contexto literario de}

\section{los años setenta}

En relación con la década precedente, los años setenta suponen un cierto oscurecimiento para el mundo intelectual de la República Federal de Alemania. Un aumento del control y de la represión política es consecuencia, entre otros motivos, de 
la postura izquierdista que la intelectualidad literaria había adoptado en los sesenta. Esta represión se refleja posteriormente en la propia literatura (por ejemplo, en la obra de Böll, de 1975, «Berichte zur Gesinnungslage der Nation»), en una literatura observada con pesimismo o, al menos, con escepticismo por críticos como Marcel Reich-Ranicki: «Tenemos libros, pero no tenemos literatura» ${ }^{17}$. Las causas que llevan a esta situación tienen su origen en la segunda mitad de los sesenta. Se producen entonces acontecimientos importantes: toma cohesión el movimiento estudiantil en la «Universidad Libre» de Berlín, y poco después el Partido Social-demócrata se hace cargo del gobierno de la República, dándose así por terminada definitivamente la posguerra, la llamada «Era de Adenauer». En el campo de la literatura se disuelve por estas fechas el «Grupo 47». Todo ello, unido a los nuevos ímpetus y ganas de cambio reinante, permitirá establecer en esta época una cesura en la historia y en la literatura alemana. Concretamente en el ámbito literario, la euforia política dará paso, tras el fracaso del 68, a nuevos fenómenos que caracterizarán la década de los setenta: un nuevo subjetivismo, el redescubrimiento del pasado y el auge de la literatura autobiográfica, fundamentalmente.

Dos son los factores que permiten a los historiadores establecer el inicio de un nuevo período en la literatura alemana posterior a 1945: el movimiento estudiantil y un llamado «cambio de tendencia». Aquel, que tuvo como base teórica a miembros de la «Escuela de Frankfurt» y a literatos como Enzensberger, Wellershoff o Heissenbüttel, y que se rebeló contra el autoritarismo, la injusticia social y en favor de la emancipación femenina, pierde unidad y se desintegra en el umbral de los años setenta. Un cierto efecto, sin embargo, de lo que habían sido los contenidos de la revuelta perduró en la sociedad y especialmente en el mundo de la cultura, de la Universidad. Pero el sistema político-social no llegaría a verse afectado porque, además, el Estado reacciona, en 1972 , con un Decreto contra los radicales que propicia el incremento de la represión. Escritores como Böll( «Die verlorene Ehre der Katharina Blum»-1974-) o PeterSchneider («...schon bist du ein Verfassungsfeind. Das unerwartete Anschwellen der Personalakte des Lehrers Kleff»-1975-) se convertirán en expresión literaria de aquellos contestatarios con obras que intentan ir en contra de la tendencia a la despolitización de los años setenta, en contra del repliegue de la literatura frente a la política. Estos casos, más o menos aislados, no impiden a críticos como Reich-Ranicki considerar que el proceso de politización de la literatura en los años sesenta trajo como consecuencia, en lugar de cambios en la política, la ruina de la propia literatura.

La crítica habla de una fase transitoria refiriéndose a la literatura alemana de los setenta. Ranicki, por ejemplo, critica la inexistencia de grupos o escuelas, de tendencias precisas y estilos definidos. Sólo individualidades es lo que ofrece la literatura alemana en esos años; figuras individuales pero no representantes de corrientes o movimientos. En todo caso, esta fase transitoria se caracteriza por un marcado subjetivismo también perceptible en la República Democrática Alemana. Las principales tendencias que en relación con ese subjetivismo se aprecian en la República Federal son: 1) El incremento de la autobiografía y de la literatura autobiográfica en general. 2) La vuelta a los clásicos

${ }^{17}$ Marcel Reich-Ranicki, «Anmerkungen zur deutschen Literatur der siebziger Jahre», Merkur, 33, Heft 369 (1979), p. 169. 
(en Handke, por ejemplo, se aprecian con claridad referencias a autores clásicos). 3) El tema del padre; elemento o derivación de la autobiografía, ya que se trata realmente de una búsqueda de la propia identidad. 4) La literatura femenina; fenómeno no exclusivo del mundo alemán, consistente en la proliferación de temas femeninos -emancipación, igualdad de derechos- que se dan en una literatura escrita por mujeres, pero sin llegar a constituir productos típicamente «feministas». En este tipo de literatura el grado de ficción suele ser escaso y se trata por regla general de experiencias personales; la narración suele girar en torno a un personaje femenino del que presenta momentos de su vida o bien su biografía entera. Suelen ser novelas muy próximas a la autobiografía o a las memorias. Gabriele Wohmann sería una de las cabezas visibles de esta tendencia, que se inicia hacia 1969, año de aparición de «Frauen», destacada obra de Erika Runge dentro de esta corriente.

En algunas ocasiones todas estas tendencias, características de los años setenta, se aprecian en un autor. Se da el caso, por ejemplo, de mujeres que escriben sobre el tema feminista desde la perspectiva autobiográfica y en cuyo relato aparece la figura del padre.

Son años en los que la búsqueda de la identidad en la literatura femenina, el apego al yo que en definitiva rezuma toda la literatura alemana de esta década no es sino consecuencia del considerable auge que el «autobiografismo» experimenta con el cambio de tendencia. Este giro hacia el interior del individuo se ha querido explicar como consecuencia del desengaño sufrido tras el fracaso de las revueltas del 68 y el endurecimiento político en la República Federal de Alemania. Sea como fuere, lo cierto es que el interés se centra ahora en loprivado, en la esfera individual; $y$, consiguientemente, el género autobiográfico florece de manera extraordinaria. Se trata de «una literatura de repliegue» ${ }^{18}$ la que domina en Alemania en esta época.

Se aprecia el auge de la literatura atobiográfica a comienzos ya de los setenta con autores como Max Frisch («Tagebuch 1966-1971»), Günter Grass («Aus dem Tagebuch einer Schnecke»), o Peter Rühmkorf ( «Die Jahre die Ihr kennt»). Dos años más tarde Hilde Domin publica «Von der Natur nicht vorgesehen»; y entre 1975 y 1978 aparecen textos autobiográficos de Thomas Bernhard, («Die Ursache», «Der Keller« y «Der Atem»), Wolfgang Koeppen («Jugend»), Elias Canetti («Die gerettete Zunge»), Peter Handke ( Das Gewicht der Welt») y Wolfdietrich Schnurre ( $(D e r$ Schattenfotograf»). También repartidas en distintos años de la década de los setenta se publican novelas de componente autobiográfico correspondientes a Walter Kempowski («Uns geht' s ja noch gold»), Christa Wolf(«Kindheitsmuster»), PeterWeiss («Die ÄsthetikdesWiderstands»), Hubert Fichte («Versuch über die Pubertät») y Max Frisch («Montauk»).

Relacionada con esta tendencia hacia lo autobiográfico se observa también una proliferación de biografías sobre escritores y compositores del pasado, cuyos autores son frecuentemente conocidos novelistas o escritores de ficción y no ensayistas o investigadores. Ejemplos en este sentido los tenemos en Peter Härtling, Wolfgang Hisdesheimer, Adolf Muschg, Dieter Kühn y Hans J. Fröhlich con textos sobre Hölderlin, Mozart, Keller, Oswald von Wolkenstein y Schubert respectivamente.

${ }^{18}$ M. Reich-Ranicki, op. cit. p. 173. 
Lo que no había conseguido -dice Sylvia Schwab- ${ }^{19}$ la politización de la literatura se busca ahora en el yo, en la esfera privada. Gran número de textos corroboran esta afirmación: autobiografía documental, entrevista autobiográfica, novela autobiográficodocumental son, por otra parte, diferentes modos de manifestarse la influencia en la narración autobiográfica del procedimiento y finalidad de la liteatura documental que, por lo demás, utilizan una metodología muy similar. Un claro ejemplo significativo es Kempowski: su novela, confeccionada con material autobiográfico, está en línea con la literatura documental. Otro tanto sirve para Erika Runge de quien -por el empleo del documento, del magnetófono, bien por falta de imaginación, bien por voluntad de experimentar algo nuevo- se ha llegado a decir que ha creado un tipo de literatura «carente de autor».

En fin, la reflexión o monólogo interior, como técnica mediante la cual se exterioriza la subjetividad aislada del entomo, es otra frecuente constante en la literatura de estos años, definidos por Volker Hage como una década de historias del yo en la que todos quieren hablar de sí mismos ${ }^{20}$.

Sin que se pueda hablar de un giro radical, lo que es indudable es que la literatura de los años setenta se enfrenta a la realidad desde otra perspectiva. La comunicación del hombre con los demás, característica de la literatura de la década precedente, desaparece como consecuencia de una fuerte «internalización» que tiene lugar a partir de los primeros años setenta. Esto no significa, sin embargo, que se haya operado una revolución en el escritor: la temática es la misma, pero evolucionada.

Tras el cambio de tendencia se ha hablado en Alemania de una nueva sensibilidad, nueva «internalización» o nueva subjetividad. Y no sólo en la literatura: la «nueva sensibilidad» es un concepto también político, sicológico y sociólogo. En el ámbito literario, el género autobiográfico, cuyo auge es consecuencia de ese giro hacia la «interiorización», se convierte en forma indirecta de mostrar la realidad mediante la conexión del propio yo con el mundo circundante, mediante la vuelta a un yo -ha dicho la crítica- que como perspectiva quizá había estado demasiado olvidado en tiempos pasados.

Por su parte Günter Herburger es una manifestación programática de 1967 parece profetizar el advenimiento de la «nueva subjetividad» al decir que «cuando escribo, en el fondo escribo acerca de mí. Todo lo que aparece son mis proyecciones. Yo soy el personaje principal» ${ }^{21}$.

El ámbito real de la experiencia personal del sujeto estaba muy debilitado, sublimado por una forma de escribir hermética y metafórica que ahora llega a su fin. En

${ }^{19}$ Sylvia Schwab, Autobiographik und Lebenserfahrung. Versuch einer Typologie deutschsprachigen autobiographischer Schriften zwischen 1966 und 1975 (Würzburg: Verlag Dr. Johannes Königshausen + Dr. Thomas Neumann, 1951), p. 9.

${ }^{20}$ Volker Hage, die Wiederkehr des Erzählers. Neue deutsche Literatur der siebziger Jahre (Frankfurt am Main, Berlin, Wien: Ullstein, 1982), p. 28.

${ }^{21}$ Günter Herburger, «Dogmatisches über Gedichte», en Was alles hat Platz in einem Gedicht?, p. 76, Nota 3 de Deutsche Literatur in der Bundesrepublikseit 1965, Hrsg. Paul Michael Lützelerund Egon Schwarz (Konigstein/Ts.: Athenäum Verlag, 1980), p. 19. 
este sentido, se habla de un redescubrimiento de la exposición lírica como manifestación de la realidad. En la «nueva subjetividad» el puesto del yo lírico lo ocupa -dice Hiltrud Gnüg- ${ }^{22}$ el yo auténtico; el lenguaje poético deja paso al cotidiano. Los contenidos metafóricos o suprarreales se sustituyen por manifestaciones de hechos concretos, no comunes o generalizados; las experiencias que se transmiten se ciñen a la realidad sin intentar ir más allá. El hombre de la «nueva subjetividad» no adopta, por tanto, una postura de «interiorización» para «huir de la realidad banal a otra más alta y llena de significado ${ }^{23}$; es un no salirse de las fronteras de lo conocido, de lo que está próximo al escritor. La política, las ideas son sustituidas por lo cotidiano, por las vivencias personales; ello hace que se hable ahora de un nuevo Realismo. No se trata, pues, de un sistema dualista de contraposición del yo conelno-yo, sino que la «unidimensionalidad» ${ }^{24}$ es la que domina.

Esta introspección típica de los años setenta tiene su lado negativo. Aunque se habla de otra perspectiva, la vuelta a la «interiorización» trae como consecuencia un descuido del mundo exterior al sujeto. Efectivamente, ahora se observa la realidad desde otra óptica; pero se observa con menor intensidad, de manera que la preocupación por problemas de tipo colectivo queda un tanto relegada porque «lo que subjetividad y sensibilidad hacen posible es precisamente lo que se ve impedido por la interiorización: la confrontación de la literatura con su época» ${ }^{25}$. Es decir, la vuelta al yo implica en la década del setenta dos cosas: un nuevo enfoque del mundo exterior al sujeto (subjetivismo) y un protagonismo del sujeto («interiorización»). Esta doble faceta sin duda ha sido la causa de las dispares valoraciones que se hacen de la literatura alemana a partir del cambio de tendencia. Para unos, «interiorización» es un fenómeno reprobable; para otros, no lo es ya que supone un nuevo tipo de sensibilidad. En cualquier caso, el hecho relevante es que una nueva forma de subjetividad domina en la literatura alemana; y es nueva porque el yo lírico, el yo sublimado por el arte, ha sido desplazado por el yo auténtico del escritor. Pero esto, que es positivo e importante desde el punto de vista de teoría e historia literaria por significar una nueva forma de manifestación artística, presenta desde la perspectiva social y política el lado negativo al que nos referíamos antes, puesto que el giro del autor hacia sí mismo puede verse como un síntoma de dejadez o «subsidiariedad» en el tratamiento de los temas que afectan a los demás. La observación indirecta de la realidad que produce el nuevo subjetivismo implica necesariamente que los problemas colectivos pasen a un segundo plano, al menos en el sentido de que el lector necesita un mayor esfuerzo para poder captarlos. Sin ese esfuerzo, su comprensión de la obra literaria resultará superficial. Y «Mein Lesebuch» 75.

${ }^{22}$ Hiltrud Gnüg, «Was heisst “Neue Subjektivităt», Merkur, 1, Heft 356 (Stuttgart: Klett-Cotta), pp. 60 -

${ }^{23}$ P. M. Lützeler und Egon Schwarz (Hrsg.), op. cit., 24.

${ }^{24}$ H. Gnüg, op. cit., p. 74.

${ }^{25}$ M. Reich-Ranicki, op. cit., p. 177. 
no es una excepción en este caso «es un libro difícil que exige esfuerzo y concentración par parte del lecton ${ }^{26}$.

Pues bien, visto lo que entraña el concepto «nueva subjetividad» en la literatura alemana actual ¿podemos decir que «Mein Lesebuch» es un fenómeno que se encuadra en esa tendencia a la introspección? ¿Qué es consecuencia de la «internalización» de estos años? Creemos que sí. Por ser, precisamente, «Mein Lesebuch» un símbolo del auge de la literatura autobiográfica, entra de lleno en la tendencia a la «interiorización», a la personalización», en la que ese tipo de literatura se inscribe.

La relación del sujeto, enriquecido por la experiencia, con el mundo exterior es precisamente lo que sucede en el «Lesebuch» subjetivo, pero limitada a una parte concreta de la realidad: aquella que vio el autor a través de su experiencia intelectual; el mundo que presentan los textos que interesan al sujeto exclusivamente.

La experiencia personal de lecturas es el presupuesto primordial de la autenticidad autobiográfica, y la autenticidad implica mostrar la verdad; por ello, «Mein Lesebuch» es, sin lugar a dudas, literatura autobiográfica. Este entronque de «Mein Lesebuch» en el género autobiográfico, $y$, por tanto, en la tendencia a la «interiorización» hace de la serie un producto genuino de la literatura alemana actual, que cae dentro de la esfera de esa nueva «interiorización» («Neue Innerlichkeit») tanto por el procedimiento subjetivo empleado en.su elaboración como por las consecuencias, por el resultado de apuntar los textos de «Mẹin Lesebuch» a una realidad indirectamente observada.

Sintetizando, «Mein Lesebuch» es un fenómeno que se enmarca dentro de la «nueva interiorización» por los siguientes motivos:

1) «Mein Lesebuch» supone una vivencia personal, una vivencia del individuo.

2) Como forma literaria «Mein Lesebuch» es un medio de comunicar experiencias.

3) Pero la comunicación de experiencias, de vivencias personales, tales como las presentadas en un «Lesebuch» subjetivo, requiere una fase previa. Cuando un autor escribe su «Lesebuch» ello significa que con anterioridad ha salido al mundo exterior (ha leído a otros autores), ha experimentado con esa lectura, se ha enriquecido intelectualmente y ahora, volviendo a sí mismo, ve la realidad exterior desde su intimidad.

4) A su vez, «Mein Lesebuch» en cotejo con la producción literaria del autor, enriquecida e influenciada con su «excursión intelectual», nos muestra cómo la realidad que exploró se refleja en su obra, desde la que ve el mundo exterior porque se ha producido -decíamos al hablar de la «Configuración del "género Mein Lesebuch" dentro del ámbito de la literatura autobiográfica»- «la aceptación y asunción de lo creado por otro y que ha pasado a formar parte del yo».

5) Los textos reunidos en el «Lesebuch» subjetivo hacen referencia a un yo auténtico desprovisto de hermetismo, que presenta hechos de lectura concretos sin ropaje de ningún tipo. El autor de «Mein Lesebuch» - y sin pensar siquiera en su posible configuración futura como autobiografía intelectual-ofrece textos precisos sin pretender

26 Jochen Vogt, «Won Minimalprogramm der Humanităt. Heinrich Bblls «Lesebuch»: Nicht zum Blättern und Schmökern». Frankfurter Rundschau, 14.10.1978. 
ir más allá; nos muestra una parte de la realidad intelectual que ha vivido y que, por lo tanto, está próxima a él.

6) Con «Mein Lesebuch» la realidad se muestra de forma indirecta. El tipo de literatura que presenta el autor revela los temas que le interesan; los problemas que encierran los textos elegidos son la parte de realidad que más especialmente preocupa al autor. Consecuentemente, el lector observa aspectos de una realidad pretérita o actual subjetivamente presentada.

7) Por tratarse de una muestra indirecta de la realidad, el lector tiene que hacer un mayor esfuerzo para captarla; en caso contrario no sale de la esfera del sujeto. Es decir, no es lo mismo leer el «Lesebuch» de Böll, por ejemplo, como antología de textos elegidos por él (y en este caso el centro de atención es el propio sujeto Böll) que como antología de una realidad observada subjetivamente por Böll (y aquí la atención sufre un desplazamiento concentrándose en una parte de la realidad y no en el sujeto, que pasa a tener para el lector un interés secundario). En el primer caso se trataría de una lectura científica de aproximación a Böll y a su obra; en el segundo, el lector se interesa por la realidad exterior al sujeto, pero dejándose guiar por éste, observa la parte de la realidad que el sujeto (compilador del «Lesebuch») ha elegido. $O$ sea, en este segundo supuesto se lee «Mein Lesebuch» como antología; en el otro caso, como obra autobiográfica.

\section{Valor de «Mein Lesebuch»}

Habría que empezar por hablar de un valor intrínseco propio de toda obra que solamente puede ser producida por un único autor. «Mein Lesebuch», como cualquier manifestación literaria autobiográfica, carece de competencia. Contrariamente, como creación propia no tiene valor. Los textos aisladamente considerados naturalmente que son creaciones literarias, pero desde el momento en que se utilizan para configurar una antología o como documentación de una autobiográfica intelectual, el compilador es esto exclusivamente y no alcanza con su «Lesebuch» subjetivo el rango de creador.

Un posible valor es el de producto editorial (si consideramos que cualquier producto por el solo hecho de imprimirse y comercializarse tiene un valor en sî). Por supuesto, es evidente que casi todo producto editorial se lanza al mercado con una finalidad lucrativa, entre otras; pero lo que sucede es que en el caso de «Mein Lesebuch» esa finalidad unida al interés de relanzar a algunos autores parece más palpable. En este terreno, sin embargo, faltan datos y, por otra parte, tampoco consideramos que tal aspecto tenga un interés excesivo. Partimos de la base de que lo importante es estudiar el fenómeno literario «Mein Lesebuch» como tal, prescindiendo de posibles intereses económicos o comerciales como planteamientos previos al lanzamiento de la serie. En todo caso, hagamos patente nuestra opinión y dejemos constancia de que, a nuestro juicio, es muy probable que la idea promotora de la serie en absoluto tuviese en cuenta las repercusiones y posibles valores que desde la perspectiva de historia y teoría literaria pudiesen sobrevenir. Lo mismo que, en multitud de ocasiones, un autor escribe una obra de literatura porque quiere comunicar algo a los demás, sin pensar ni prever en muchos casos el resultado que desde el punto de vista estético va a alcanzar su trabajo, «Mein 
Lesebuch» tuvo muy probablemente un origen en el que pesó más el interés editorial que el valor en sí del libro. El caso del Böll es bastante clarificador a este respecto. Cualquier editorial sabe que un «Lesebuch» de un autor conocidísimo, Premio Nobel además, se vende con facilidad ${ }^{27}$; y no sólo se vende, sino que populariza la expresión «Mein Lesebuch», abre camino para futuros «Lesebücher» de autores ya no tan conocidos. Otras veces un buen motivo comercial para publicar un «Lesebuch» puede ser el éxito que ha tenido recientemente el autor de tal «Lesebuch» con una obra de creación; este pudiera ser el caso de Michael Ende que ha alcanzado enormes cotas de popularidad con «Die unendliche Geschichte» (La historia interminable) y poco después, en octubre de 1983, sale al mercado su «Lesebuch».

En fin, prescindiendo de toda clase de posibles motivaciones extraliterarias, vemos en «Mein Lesebuch» un doble valor que le viene, por un lado, de su carácter autobiográfico; por otro, de su carácter antológico.

$\mathrm{El}$ «autobiografismo» otorga a «Mein Lesebuch» un valor erudito; valor importante no para el lector ocasional, sino para el científico de la literatura, para el estudioso, para el historiador y para todo aquel que quiera acercarse a la personalidad del autor. En la investigación literaria el «Lesebuch» subjetivo proporciona al investigador referencias, datos y orientaciones de gran valor y utilidad para profundizar en la personalidad del autor del «Lesebuch», porque estos «Lesebücher» son «un autorretrato a partir de textos ajenos» ${ }^{28}$. A su vez, al crítico literario se le facilita su labor interpretativa y dispone, con el «Lesebuch» subjetivo, de un instrumento que le permitirá precisar con mayor exactitud en sus análisis de obras de creación del autor del «Lesebuch» correspondiente.

El otro valor que vemos en «Mein Lesebuch», y que -según decíamos- le viene de su carácter antológico, es el de ser medio para el conocimiento de la historia de la literatura. Cualquier «Lesebuch» subjetivo es también una historia de la literatura a través de los textos; en unos casos será literatura nacional, en otros universal; a veces se sigue un orden cronológico, otras veces el «Lesebuch» se centrará en una época, en un género o en un estilo literario. Siempre será, sin embargo, historia de la literatura. De cómo esté hecho el «Lesebuch» resultará, en todo caso, un subvalor (no en el sentido de menor importancia; sino que sería un apartado dentro del valor más genérico de «conocimiento de la historia de la literatura») de proyección de un determinado tipo de estética.

\section{Textos similares a «Mein Lesebuch». Futuro de la serie}

Además de los «Lesebücher» escolares y de las antologías clásicas, existen en el ámbito alemán textos que guardan semejanza con los de la serie que nos ocupa. Quizá

${ }^{27}$ En el caso de Böll, de 120.000 ejemplares se han vendido cerca de 118.000 . Le sigue a considerable distancia el «Lesebuch» de Luise Rinser que de 50.000 ejemplares se han vendido 48.000. (Datos facilitados en carta personal de la editorial Fischer Taschenbuch Verlag).

${ }^{28}$ Rolf Michaelis, «Eine neue Art von Anthologie: Selbstportrait aus fremden Texten. Mein Lesebuch mein Pass», Die Zeit, 10.12.1976, p. 33. 
el más distante por su finalidad sea el libro «Turrini Lesebuch» ${ }^{29}$. Se aleja de la serie porque no es una selección subjetiva de textos. En realidad se trata de la presentación de la obra de Turrini bajo un enfoque diferente para conseguir, según se dice en el prólogo, un «Lesebuch alternativo», un «Lesebuch no afirmativo sino crítico».

Del mismo estilo que los libros de la serie «Mein Lesebuch» se ha publicado en la editorial «dtv» «Mein erotisches Lesebuch» ${ }^{30}$, de Barbara Bronnen. Se trata de la misma idea: «Para la presente antología Barbara Bronnen ha hecho una selección muy personal», se dice en la primera página del libro. Es, pues, una reunión también de textos subjetivamente seleccionados pero referidos exclusivamente al campo de la literatura erótica escrita por mujeres.

Una posible mejora a «Mein Lesebuch» podrían ser obras del tipo «Erste LeseErlebnisse» ${ }^{31}$. Concretamente en este caso, un editor reúne en un mismo volumen las primeras experiencias de lectura de diversos escritores narradas por ellos mismos. Se trata, por tanto, de las lecturas de juventud de una serie de autores en donde ya interviene, aunque tímidamente, el elemento creativo. El punto de partida es también subjetivo, como en «Mein Lesebuch»; los diversos autores que intervienen se recrean en las lecturas que más le impresionaron de jóvenes: comentan el recuerdo, el sabor de aquellas lecturas, los temas que fueron de su interés. No llegan, sin embargo, a una auténtica re-creación, como en España, por ejemplo, hace Fernando Savater en La infancia recuperada y en Criaturas del aire. En general no se citan textos tan concretos como en «Mein Lesebuch», sino autores u obras completas: Ana Seghers, por ejemplo, menciona a Schiller y a Dostojewski; Hans Erich Nossack a Hebbel; Martin Walser a Hölderlin. En algunos casos, en cambio, sí se hace referencia a algún pasaje determinado: Peter Weiss habla, por ejemplo, de algunos pasajes de «Le Rouge et le Noir», de Stendhal. Este último caso sería, en nuestra opinión, una especie de «Mein Lesebuch» más perfeccionado, pues no se trata de la mera selección subjetiva de unos párrafos de obras literarias, sino que se explica un poco el porqué de ese texto en concreto, mediante el desarrollo de un breve comentario. De todas formas, como normalmente en «Erste LeseErlebnisse» sólo se ofrece el comentario del autor remitido al texto que cita pero generalmente éste no se incluye, el valor como antología o «Lesebuch» desaparece. Por eso, el ideal sería un tipo de libro que, sin perder las características de «Mein Lesebuch», se enriqueciera con la aportación personal del autor. Es decir, se trataría de presentar el texto subjetivamente seleccionado y, a continuación, una reseña explicativa del porqué de ese texto.

Otra variante es la que presenta la editorial «Luchterhand» bajo el título «Mein Lektüre». Dos son los que hemos manejado, sin que tengamos noticia de la existencia de más: uno de Gabriele Wohmann y otro de Peter Härtling ${ }^{32}$. El texto de Wohmann está

${ }^{29}$ Peter Turrini, Turrini Lesebuch. Stücke, Pamphlete, Filme, Reaktionen etc. Ausgewählt und bearbeitet von Ulf Birbaumer (Wien: Europaverlag, 1975).

${ }^{30}$ Barbara Bronnen (Hrsg.), Mein erotisches Le sebuch (München: Deutscher Taschenbuch Verlag, 1983).

${ }^{31}$ Siegfried Unseld (Hrsg.), Erste Lese-Erlebnisse, (Frankfurt am Main: Suhrkamp Verlag, 1975).

${ }^{32}$ Pcter Härling, Meine Lektüre. Literatur als Widerstand. (Darmstadt: Sammlung Luchterhand, 1981). Gabriele Wohmann, Meine Lektüre. Aufsätze über Bücher (Darmstadt: Sammlung Luchterhand, 1980). 
concebido bajo una perspectiva de crítica literaria. En realidad, son recensiones críticas, casi todas publicadas con anterioridad en periódicos y revistas, y que ahora el editor reúne en un solo tomo. En principio diríamos que estamos ante un texto menos vivencial, más objetivo que «Mein Lesebuch», si bien es cierto que se trata de experiencias de lectura relatadas desde un punto de vista crítico-personal, que sirven al lector para profundizar en la escritora Gabriele Wohmann.

El libro de Härtling, muy similar, se diferencia, en cambio, del texto de Wohmann en estar escrito en forma más ensayística. Lo que hace el editor en este caso es reunir una serie de ensayos de Härtling que están enfocados hacia la figura y las obras de escritores más que sobre aspectos concretos de un texto determinado, aunque manteniendo también un fuerte subjetivismo.

Como se ve, el elemento subjetivo domina en casi todos los ejemplos citados como una constante de los años en los que aparece la serie objeto de este artículo, del mismo modo que veíamos el fuerte componente autobiográfico en buen número de obras de creación al hablar de la literatura de los setenta y de la «nueva subjetividad».

De los libros que hemos citado como similares a los de la serie «Mein Lesebuch», salvo el de Barbara Bronnen, los demás se separan bastante, al menos formalmente, del sentido de «Mein Lesebuch». El de Turrini tiene otras metas y no se trata además de un «Lesebuch» subjetivo. Los otros adquieren mayor interés por cuanto en ellos interviene la creatividad del autor; sin embargo, pierden el carácter de antología y entran en el campo de la crítica, el ensayo o la recensión.

En lo que se refiere al porvenir de la serie «Mein Lesebuch», lo único que sabemos con certeza es que continuará ampliándose porque está prevista la publicación de próximos «Lesebücher» ${ }^{33}$. A largo plazo no podemos saber, sin embargo, el futuro que pueden tener libros de este tipo. Es difícil, por no decir imposible, tratar de aventurar lo que sucederá con «Mein Lesebuch» en los próximos años. En cualquier caso, pensamos que se trata de un experimento de futuro incierto en cuyo éxito o fracaso intervendrán diversidad de factores. Por lo demás, y con independencia de los valores estéticos, divulgativos u otros que puedan verse en «Mein Lesebuch», un «Lesebuch» subjetivo -y en esto se diferenciará siempre de cualquier otro tipo de antología-tendrá condicionada su existencia al renombre del compilador. Quien quiera leer buena literatura no recurrirá a un «Lesebuch» del tipo de la serie «Mein Lesebuch» si no es por la atracción que ejerce el nombre del autor-compilador. El lector puede, en efecto, sumergirse en la historia de la literatura y saborear el placer de la lectura de la mano de Heinrich Böll o Alfred Andersch; pero, en definitiva, si lo hace, normalmente será para penetrar en la interioridad intelectual de Böll o de Andersch.

${ }^{33}$ Horst Bienek o Günter Wallraff son, por ejemplo, nombres selcccionados por «Fischer Taschenbuch Verlag», según nos consta por comunicación directa de la editorial. 


\section{Conclusión}

En los «Lesebücher» se inserta la siguiente leyenda: «Bajo el título "Mein Lesebuch", la editorial Fischer Taschenbuch publica antologías en las cuales escritores de hoy presentan textos de la literatura universal elegidos de forma totalmente subjetiva». Sin embargo, la concepción del autor varía en ocasiones, ya en cuanto al aspecto subjetivo, ya en lo referente a la universalidad de la literatura escogida. Esa libertad que se toma el autor supone, no obstante, un margen de movimiento aceptable y que no conculca en lo fundamental los principios inspiradores de la serie.

Por otra parte, en estos se habla de escritores de hoy, y nosotros, aceptando la sugerencia de Böll en el prólogo a su «Lesebuch», propondríamos una ampliación a personajes no literatos. Sería interesante que hicieran su «Lesebuch» personalidades de la vida pública, del mundo intelectual, del arte o de la política. Porque, si en la literatura de creación la obra interesa por sí misma, muchas veces independientemente, incluso, de quién sea su autor, en el «Lesebuch» subjetivo raras veces esto será así. Generalmente un «Lesebuch» de esa naturaleza es objeto de atención por cuanto refleja la personalidad del autor y sirve para profundizar en su autobiografía intelectual; es decir, el «Lesebuch» está en función de su autor, principalmente. Por ello, un «Lesebuch» de alguien anónimo y desconocido en cualquier ámbito de la actividad intelectual, artística, política, o simplemente irrelevante en cualquier manifestación de alcance social carece de valor. Sólo si el autor es persona conocida por su quehacer en alguna de las ramas mencionadas, cobra sentido el «Lesebuch» subjetivo.

En consecuencia, «Mein Lesebuch» tiene para el público en general que prescinda del nombre del compilador un valor muy relativo, justificable quizá sólo por lo que un «Lesebuch» subjetivo pueda suponer de actitud rebelde frente a la crítica establecida, ya que en «Mein Lesebuch» el lector puede encontrar una serie de textos que difícilmente hallaría en otro tipo de antologías.

Por lo demás, poco resta que añadir a toda una serie de conclusiones que de forma dispersa se han ido apuntando. Recordemos esquemáticamente las principales:

1) «Mein Lesebuch» es literatura, pero no innovación; no es creación artística, sino actividad editora o compiladora.

2) «Mein Lesebuch» es un nuevo tipo de antología literaria que tiene su lejano antecedente nominal y estructural en las antologías escolares.

3) «Mein Lesebuch» presenta lo mejor desde una perspectiva subjetiva. Es decir, en antologías de esta naturaleza el autor muestra qué es lo que más le ha impresionado, influenciado o fascinado de entre aquellas lecturas que realizó a lo largo de su vida. La selección de textos que ofrece en su antología personal es, por tanto, una presentación de la mejor literatura que ha leído.

4) «Mein Lesebuch», como una nueva manifestación del hecho autobiográfico, es un símbolo del auge de la literatura autobiográfica y de la tendencia intimista de la literatura alemana de los años setenta y ochenta.

5) «Mein Lesebuch» tiene una doble funcionalidad, como libro de lectura y como fuente de investigación. En el primer caso es una antología que proporciona placer 
estético y conocimiento de la historia de la literatura; en el segundo, es un documento lleno de referencias sobre el desarrollo intelectual del compilador. En este sentido «Mein Lesebuch» nos acerca al mundo intelectual de un individuo porque al estar compuesto por fragmentos de obras de gran importancia para el compilador, adquiere automáticamente el carácter de documento utilizable en un posible proyecto de autobiografía intelectual.

Por consiguiente, no es todavía autobiografía pura porque le falta el componente que Misch hace observar como esencial en la obra autobiográfica: la forma. Esta carencia limita a «Mein Lesebuch» a un aspecto para elaborar la definitiva autobiografía. El material que se utiliza es el documento, y cuando éste se aporta respondiendo a una actitud sincera, «Mein Lesebuch» es una antología de gran autenticidad.

6) «Mein Lesebuch» es un experimento literario-editorial que por sus peculiares características se presta a la manipulación; en él pueden jugar un papel importante los intereses editoriales. Con libros de esta naturaleza se puede relanzar a un autor o mantener actuales a otros que atraviesan por una fase de sequedad creativa.

Resumiendo: «Mein Lesebuch» adquiere relevancia dentro de la literatura alemana actual por resultarun nuevo tipo de antología que entronca con la literatura autobiográficodocumental dentro del ámbito de la «nueva subjetividad». 